\title{
GUEST EDITOR'S NOTE ON DIGITALIZATION IN LAW
}

\author{
MICHAL RADVAN, \\ Masaryk University (Brno, Czech Republic)
}

https://doi.org/10.21684/2412-2343-2020-7-2-5-9

Recommended citation: Michal Radvan, Guest Editor's Note on Digitalization in Law, 7(2) BRICS Law Journal 5-9 (2020).

Digitalization is a phenomenon of the last two decades. This term is very often used in everyday life, in the economy, in the scientific literature, etc. There are completely new business sectors. The digitalization touches all spheres of life, including law. However, do we really know what does the term itself mean? Can we describe and analyse the impact of digitalization in law? Is it necessary to digitalize law? What are the benefits of digitalization in-law/of law? And are there any threats connected with this process? I believe that the following articles in this special issue have the potential to at least partially answer some of these questions regarding the selected areas.

Generally, digitalization is a generic term used for the digital transformation of the economy. However, other similar terms are used very often (and by the authors of the following articles as well) as synonyms: digitization and digital transformation. Digitization was the first step, as it means transitioning from analogue to digital. It is the process of making all paper information available and accessible in digital format, the material process of converting analogue streams of information into digital bits. ${ }^{1}$ Digitalization follows, as digitized data creates the potential for applications that facilitate standard work practices. Digitalization is the way many domains of social life are restructured around digital communication and media infrastructures. ${ }^{2}$ Digital transformation is then the third step, as thanks to digitization and digitalization, new business concepts are created.

\footnotetext{
J. Scott Brennen \& Daniel Kreiss, Digitalization in The International Encyclopedia of Communication Theory and Philosophy. Vol. 4556 (K.B. Jensen et al. (eds.), Hoboken, N.J.: Wiley, 2016).

2 Id.
} 
The topic of digitalization of law includes all three above-mentioned terms and stages. Digitalization influences all branches of law. There are many examples of digitization, digitalization and digital transformation. For instance, in the area of property law: two decades ago, property was registered in the paper database. Nowadays, all data is digital. Thanks to this, creating online databases of properties in each country was made possible. Many stakeholders such as state offices, banks, insurance companies, etc. and sometimes the whole community have online access to the cadastre. The cadastre includes all the basic information about the property type, size, structures on it, location, price, sometimes even property tax, etc. And such a complex source of information creates new possibilities for business (e.g. zillow. com, etc.).

Digitalization in law is very much influenced by the economic and technical development. Political decisions are crucial for legal regulation, as well. The best example seems to be Estonia, where $67 \%$ of Estonians use ID-cards regularly, $99 \%$ of State services are online, and almost one half of Estonians is using internet voting. In 1994, the first draft of the Principles of Estonian Information Policy was made. Since 1996, people can use an e-banking service. In 2000, an e-tax board was established, and since 2002, e-ids and digital signatures are being used. The first i-voting took place in 2005, and the complex Government Al strategy was announced in $2019 .{ }^{3}$

Legal regulation should be adequately prepared for these political decisions, respecting economic and technical development.

This implies that the large-scale digitalization processes that have engulfed the whole world pose an important challenge for the law to adapt to the new digital conditions. Modern legal science plays a very important role in this challenge. It must lay the fundamental theoretical foundations for the adequate legal regulation of transforming social relations.

Legal scholars around the world are engaged in the study of law and digital transformation today to achieve this goal. Whether acting alone or in teams, they seek to develop concepts for the modern legal regulation of the digital environment that can be transferred into effective tools and mechanisms.

In this regard, the research activity of the scholars in the International Interdisciplinary project LegalTech: Legal Regulation of Artificial Intelligence, Robotics, Digital Economy, and Creating Smart Law for Smart Industry must be mentioned. This will create the concept of legal regulation of LegalTech and scientific doctrine of digitalization of law.

The project had been started in 2018 by the scientists of the Institute of Law of South Ural State University. Today, under the guidance of Elena Titova, Director of the Institute of Law of South Ural State University, this project brings together researchers with different field of expertise from Russia, Poland, Slovenia, Serbia, Malaysia, India,

\footnotetext{
3 Digital portal "e-estonia" (Mar. 28, 2020), available at https://e-estonia.com.
} 
Italy and the UK. Research papers on the most topical issues of digitalization of law were published in highly ranked journals within the project. Collections of articles Smart Law for Smart Industry had been published recently. The work on a collective monograph Law for Digital Environment is ongoing.

The collection of research papers represented in this Special Issue deals with the problems of digitalization of different branches of law which is highly important. All branches of law will be covered. In most of the branches, there are hidden challenges of digitalization, especially in private law. We can assume that most of the contracts will be in electronic form in the near future. Lawmakers should then prepare adequate legal regulation regarding electronic signatures. We should think of smart internet contracts, i.e. contracts written electronically, by the application, and without the active participation of lawyers. We have to define digital property and decide whether the regulation de lege lata in civil codes is sufficient for such property. We have to investigate online contracts concerning the protection of consumers. The last issue was the topic of Prof. dr. Elena Ostanina and Prof. dr. Elena Titova in this journal.

There are many questions connected with e-Liability. It is necessary to decide who takes the blame and who is responsible when no human is at fault. Who pays for the mistake of a smart car? In the inheritance law, there are many issues connected with digital heritage. What will happen with our Instagram, Facebook and Twitter accounts after our death? I can see a lot of advantages in Economy 4.0; however, it is necessary to deal with some issues, especially in the labour law area and connected branches of law, namely social security law. We can assume that workers will be replaced by robots; should Labour Codes be applied to robots, too? Do we need a new regulation if many people become homeworkers and teleworkers (especially now in the time of COVID-19) and if working hours become a useless instrument? Last but not least, in the private law sphere, IT law is becoming more and more important. E.g. is there a right to be forgotten?

The benefits of digitalization are visible in public law, too. In the public law sector, we should deal with E-government, E-voting, and E-administrating. Concerning the banking and finance sector, could you imagine paper stocks and bonds nowadays? The capital market is fully changed due to digitalization, and the old ways of stock trading can be seen in movies only. The ratio of cash and credit card payments has also changed. In COVID-19 crises, it is advised to pay by cards only. We are not limited to only use national currencies, as there is a wide portfolio of virtual currencies as well. I am afraid most of the national regulations are not ready for this evolution. The article on the ecosystem of cryptocurrency as an object of civil rights by Natalya Dulatova and Abd Hakim Abd Razak might be useful for both the national legislators and those who are using cryptocurrencies.

The antitrust legislation is influenced by the digital economy, too. The price algorithms as a threat to competition under the conditions of digital economy is the topic of Alena Spiridonova and Edvardas Juchnevicius. 
My specialization is tax law, which is the oldest branch of law. It occurred with the first states. The first sovereigns did not deal with contract law or business law. They were not protecting Human Rights, and they did not want to have any constitutions. They primarily needed money so that they could rule over their territory. The tax law was born, even if it was probably more on tax than on law. Nowadays, taxpayers have rights and obligations, but taxes are still hated. Digitalization might be a tool to make tax payments at least a bit more comfortable. You can fill the tax return electronically, very often with the application automatically doing most of the calculations. You can send the forms electronically to the tax office, and you can make an online payment. Tax administration may use digital tools to control your taxes. There are also new instruments like electronic revenue registries.

Here comes another area that should be precisely regulated. In the era of Big Brothers, all data must be protected. In the field of criminal law, it is necessary to include the definitions of cybercrimes. We should remember negative aspects such as sexual harassment in virtual reality. What is the liability of website operators for comments (hate speech) of others? Cyber criminality has no borders. In their article, Prof. dr. Evgenii Nikitin and Dr. Mensah Cocou Marius analysed a joint system for preventing international crime and stated the necessity of creating a Unified Digital Environment for Law Enforcement Services. This implies the speed of achieving the objectives of law enforcement, reduction of corruption risks, and automation of individual work processes by replacing the human resource with software.

There is no doubt that digitalization is changing our lives, our thinking, behaviour, and decision-making. But how about the legal regulation? For sure, legal regulation is always one or two steps behind the real life. Is it necessary to change regulation de lege lata adequately, too? The answer is not easy and depends on the object of regulation. For example, if we decide to tax robots, we have to create a completely new regulation, as contemporary norms are applicable only on natural persons and corporations.

On the other hand, in case of sharing economy, we can apply existing tax law norms on the new types of business. E.g. for the Airbnb types of accommodation, there are three existing possibilities of taxing the income: 1. as an income from an independent activity/business if it is a real regular business with other services similar to hotel accommodation; 2 . as a rental income if the property is only rented without additional services; 3 . as an other income if it is a one-time rent of property, i.e. an original idea of Airbnb accommodation, when you leave for a holiday and other people are staying in your property. Then it is a task for the State and its authorities to investigate if the sharing economy activities are legal or if they are a part of an underground economy. And of course, they can use electronic (digital) tools to get evidence (internet databases and platforms, Google maps, Street View, etc.).

As it is obvious from the above-mentioned text, law is touched by all three terms: digitization, digitalization, and digital transformation. Definitely, law is always 
behind the technical and economic development. If it occurs that the regulation is not adequate for new relations, it is necessary to create new legal rules to meet the aims of the policymakers. Legislators should create favourable conditions to apply new digital technologies safely and beneficially. One of the possible tools is a regulatory sandbox. Prof. dr. Elizaveta Gromova and Prof. dr. Tjaša Ivanc believe that its application aimed at encouraging innovation activities by allowing business entities to test their offerings in a safe environment, provide an example of a shift away from traditional regulatory approaches and represent an attempt to embrace principles of proactive, dynamic and responsive regulation.

Progress is necessary, and digitalization is a substantial part of progress. Even lawyers need digitalization in their profession. Do you remember that 20 years ago, there was only a paper collection of acts? Maybe some of you still have decoratively bound yearbooks of collections in your offices. Yes, it is nice on professional business photographs or when being interviewed for national TV. But do you also remember cutting out the amendments of the acts and pasting these amendments into the original acts to have the latest versions? Nowadays, we have automatic systems of laws where you can find any act, any keyword, any related court's decision, etc. Moreover, you can switch between the terms of effectiveness. That is why nobody is obliged to read the sentence: "Word number" is replaced by "word word" and "words by number" are replaced by "words by words." 